\title{
EL ESTUDIO DE LAS RELACIONES INTERNACIONALES EN MÉXICO, 1990-2020: DEL FIN DEL ORDEN BIPOLAR A LA PANDEMIA DEL COVID-19
}

INTERNATIONAL RELATIONS IN MEXICO, I990-2020: FROM THE END OF BIPOLAR ORDER TO THE COVID-I9 PANDEMIC

\section{Laura del Alizal Arriaga*}

\section{RESUMEN}

En este artículo se hace una revisión de trabajos publicados por profesores de universidades y centros de investigación mexicanos en donde se realiza investigación en relaciones internacionales, en un periodo caracterizado por una transformación en el orden internacional y en la política exterior de los Estados, que condujo a decisiones como el inicio de la integración económica formal en América del Norte. La importancia del proceso explica el interés por estudiar el alcance de la propuesta, analizar los cambios ocurridos y sus consecuencias a lo largo de la vigencia del Tratado de Libre Comercio de América del Norte, ahora Tratado México-Estados Unidos-Canadá, así como profundizar en el conocimiento de la migración México-Estados Unidos, el gran tema pendiente en esos tratados. Este esfuerzo se ha hecho a partir de distintas perspectivas teóricas y enfoques novedosos en el estudio de la política exterior mexicana, los cuales se seńalan a lo largo del texto.

Palabras clave: Relaciones internacionales, universidades, centros de investigación, URss, Estados Unidos, política exterior mexicana.

\section{ABSTRACT}

This article reviews papers published by professors from mexican universities and research centers where research is carried out in international relations, in a period characterized by a transformation in the international order and foreign policy of States, which led to decisions such as the beginning of formal economic integration in North America. The importance of the process explains the interest in studying the scope of the proposal, analyzing the changes that have occurred and their consequences throughout the term of the North American Free Trade Agreement, now the United States-Mexico-Canada Agreement, as well as deepening knowledge of the Mexico-U.S. migration, the big issue pending in these agreements. This effort has been made from different theoretical perspectives and novel approaches in the study of mexican foreign policy, which are noted throughout the text.

Keywords: International relations, universities, research centers, UsSR, United States of America, Mexican foreign policy.

Recibido II de abril de 2021 y aceptado 28 de mayo de $202 I$

${ }^{*}$ Profesora de Tiempo Completo, Departamento de Sociología, Universidad Autónoma Metropolitana Unidad Iztapalapa. <laa@xanum.uam.mx>. 
$\mathrm{D}$ os acontecimientos trascendentales marcan la realidad internacional en el lapso de los tres últimos decenios. El primero es el fin del orden bipolar creado al finalizar la Segunda Guerra Mundial, encabezado por dos superpotencias rivales, los Estados Unidos (EE. UU.) y la Unión Soviética (URSS), poseedoras de armas nucleares y, por este hecho, capaces de destruirse una a otra sin que sus ejércitos libraran una lucha armada (Hoffmann, 1985). El segundo, el inicio de la pandemia del Covid-I9 que cambió de golpe la normalidad de miles de millones de seres humanos en el planeta, y está teniendo severas consecuencias en términos de pérdida de vidas humanas, crisis económica, desempleo, aumento de las desigualdades y afectaciones a la salud mental de niños, jóvenes y adultos obligados a aislarse para enfrentar los estragos de un virus nuevo, altamente contagioso, identificado poco tiempo después de hacer su aparición como SARs-CoV-2.

Entre estos dos límites del periodo ocurrieron transformaciones en prácticamente todos los ámbitos de la vida, alimentadas por las tecnologías de la información y la comunicación (TIC) que, al haber transformado la noción del tiempo y del espacio, se encuentran en la base de la globalización, comenzando por la financiera, que hizo posible que los mercados ubicados en diversas partes del planeta se encuentren conectados en tiempo real (Giddens, 1999). Pero no solo la magnitud de los intercambios de capitales y mercancías ha crecido de manera sorprendente, el flujo del conocimiento generado por la investigación científica y tecnológica ha sido más intenso que nunca. Los actores de la sociedad civil, como grupos de científicos y organizaciones no gubernamentales (ONG), aparecieron en la escena política internacional con formas más eficaces para hacerse escuchar sobre la urgencia de atender el deterioro del medio ambiente provocado por las actividades económicas; sus demandas fueron presentadas de manera directa en la Cumbre de la Tierra (Río de Janeiro, 1992), organizada por Naciones Unidas, en cuya declaración final se incorporó la noción de desarrollo sostenible. El rechazo a la visión del desarrollo prevaleciente hasta entonces, que había sido denunciada desde 1972 por el Club de Roma, llevó a la creación en 1990, por parte del Programa de Naciones Unidas para el Desarrollo, de un indicador sobre desarrollo humano basado en los trabajos de Amartya Sen, para clasificar a los países, no de acuerdo con su producto interno bruto (Рів), sino según «la libertad y la oportunidad de su población de llevar una 
vida que valorara» (PNUD, 2020). También relevante fue la fuerza cobrada por las demandas para dar cabida a la diversidad de género, cultural, étnica o religiosa asociada en muchos casos a los crecientes flujos migratorios, pero que ha obligado a replantearse la inclusión de la diversidad en el interior de cada sociedad desde la base misma, es decir, la familia (Giddens, 2000; Beck, 1992; Beck, 2007). El cambio, en apenas seis lustros, ha sido acelerado y sus efectos se advierten en todos los niveles, desde el planetario hasta la vida cotidiana de los individuos.

En el transcurso de estos años se han materializado algunos de los riesgos previstos por los autores que teorizaron sobre la globalización en la década de los noventa. El riesgo global se expresa en las amenazas medioambientales que se ciernen sobre el planeta, las cuales crecen día a día sin que quienes toman las decisiones políticas y económicas parezcan comprender sus consecuencias. También han crecido los riesgos de pandemias como la actual que han agudizado la incertidumbre provocada por la pérdida de la seguridad que antes ofrecían los gobiernos, los cuales han quedado atrapados en la ineficacia y falta de credibilidad. La profundización de la brecha de desigualdad económica y social intra e ínter países constituye una amenaza a la paz interna e internacional. La visión cosmopolita de la democracia, que tiene como valor central el reconocimiento de la diversidad y como fundamento el pluralismo cultural, ha provocado una polarización política que ha partido por la mitad a sociedades de países desarrollados y, en los dos tipos de países, desarrollados y en desarrollo, han aparecido señales de un retroceso democrático que se manifiesta en la llegada al poder de dirigentes con aspiraciones autocráticas y seguidores intransigentes en sus posturas nacionalistas, ideológicas, étnicas o religiosas.

La transformación del mundo constituye el telón de fondo de la labor de investigación realizada por los estudiosos de las relaciones internacionales en México durante el tiempo de vida de la revista Polis. Como se verá a lo largo de este trabajo, la producción académica en la disciplina está estrechamente ligada a la docencia y la investigación que se realiza en universidades y centros de investigación del país. La Universidad Nacional Autónoma de México (Unam) y El Colegio de México (Colmex), instituciones en donde surgen la enseñanza universitaria de la disciplina -1951, en la Escuela de Ciencias Políticas y Sociales, con el nombre de Ciencias Diplomáticas; 
1960 como Relaciones Internacionales en el Colmex ${ }^{-2}$ y los primeros libros y revistas académicas especializadas -Foro Internacional, 1960; Relaciones Internacionales, 1973- siguen ocupando un lugar destacado tanto en la formación de profesionales como en la producción de conocimiento en relaciones internacionales. Sin embargo, un aspecto a resaltar en el desarrollo de la disciplina a partir de los ańos noventa es el crecimiento -en términos numéricos, pero más importante aún, en calidad y diversidad de enfoques o propósitos-, de los trabajos publicados sobre relaciones internacionales.

En las páginas de Polis, Cristina Puga ha mencionado que el fortalecimiento de la generación de conocimiento en las ciencias sociales en el país a partir de esos años está vinculado con la expansión de la educación superior y el impulso a la investigación por parte del Consejo Nacional de Ciencia y Tecnología (Conacyt), la Secretaría de Educación Pública (Sep) y las políticas adoptadas por diferentes universidades y centros de investigación. La importancia de la creación del Sistema Nacional de Investigadores (SNI), con sus virtudes y defectos, ha sido reconocida, en términos generales, en este proceso; sin embargo, se ha prestado menor atención a la creación de posgrados, que ella destaca (Puga, 20I2). En efecto, el desarrollo de los programas de posgrado ha sido decisivo para elevar la calidad y diversificar los temas y los enfoques utilizados en los estudios de relaciones internacionales. No hay duda de que el Programa Nacional de Posgrados de Calidad (PNPC) es el otro pilar que sostiene el avance de las ciencias sociales en el país.

La enseñanza de las relaciones internacionales se robusteció de manera significativa en el lapso cubierto en este artículo. En la Ciudad de México se crearon programas de licenciatura en el Instituto Tecnológico Autónomo de México (Itam, 1992), el Centro de Investigación y Docencia Económicas (Cide, 1993), la Universidad Iberoamericana (1994) y en numerosas universidades en diferentes entidades federativas, públicas y privadas. En su libro sobre la carrera de las relaciones internacionales en México, Luis Ochoa Bilbao

${ }^{2}$ Hay información respecto a que la primera institución que ofreció, en 1950, la carrera de Relaciones Internacionales a nivel licenciatura fue el Mexico City College, que años después se convirtió en la Universidad de las Américas. Sin embargo, como hizo notar Mario Ojeda, es necesario precisar los datos obtenidos al respecto, porque genera dudas que el primer titulado de esa licenciatura lo haya hecho en I95I, a solo un año de la creación del programa. 
identificó 87 instituciones que la ofrecen, algunas con una denominación diferente y ciertamente con nivel de calidad disímil (Ochoa Bilbao, 20II).

$\mathrm{Al}$ incremento de opciones para estudiar la licenciatura, se añade la ampliación de la oferta de programas de maestría y doctorado. En la Unam se reorganizaron los posgrados de la institución y la Facultad de Ciencias Políticas y Sociales (FCPys) está a cargo de dos programas de maestría relacionados con la disciplina: la Maestría en Estudios en Relaciones Internacionales y la Maestría en Estudios México-Estados Unidos, mientras que el Doctorado en Ciencias Políticas y Sociales cuenta con una especialidad en Relaciones Internacionales. La Universidad Autónoma Metropolitana Unidad Xochimilco (UAM-X) ofrece la Maestría en Relaciones Internacionales; el Instituto Mora, la Maestría en Cooperación Internacional; la Universidad de Guadalajara (UdeG), la Maestría en Relaciones Internacionales de los Gobiernos y Actores Locales; la Benemérita Universidad Autónoma de Puebla (BUAP), la Maestría en Relaciones Internacionales y Derechos Humanos.

En otros posgrados hay líneas de generación de conocimiento o áreas de especialización en relaciones internacionales o algunos de los temas prioritarios de la agenda bilateral México-Estados Unidos y de las relaciones con la región centroamericana. Entre estos se encuentran la Maestría y el Doctorado en Ciencia Política del Colmex; la Maestría y el Doctorado en Ciencia Política del Cide; el Doctorado en Ciencias Sociales en el Área de Estudios Regionales y la Maestría en Estudios de Población del Colef y la Maestría y el Doctorado en Estudios Sociales Línea de Procesos Políticos de la UAM Unidad Iztapalapa (UAM-I). Vale señalar que en este último grupo se encuentran los programas que cuentan con el más alto reconocimiento en el PNPC a nivel nacional.

El dinamismo observado en la enseñanza e investigación en relaciones internacionales ha sido propulsado en gran medida por la transformación de la realidad a que se hizo referencia en el inicio de este trabajo. El cierre de una etapa caracterizada por la existencia de dos grandes potencias que encabezaban sendos bloques rivales; la globalización y sus efectos en diversos ámbitos, incluida la revitalización de la integración económica con la formación de nuevos bloques, incluida la zona de libre comercio de América del Norte, así como la necesidad acuciante de atender los problemas globales por medio de la cooperación internacional, la participación de México en 
foros multilaterales para promover respuestas y el tema siempre presente de las relaciones con países y regiones dentro y fuera del continente americano, son algunos hechos que están en la base del creciente interés por la disciplina. No puede dejarse de lado el clima de reflexión y debate sobre el proceso de cambio mundial que existe en las universidades y centros de investigación, y que la Asociación Mexicana de Estudios Internacionales (AMEI) ${ }^{3}$ y otras asociaciones académicas de estudiosos de la realidad internacional han promovido al ofrecer, mediante congresos y eventos diversos, un espacio para el intercambio de ideas a nivel nacional de un cada día más nutrido grupo de internacionalistas.

La posibilidad de una revisión de las aportaciones de los estudiosos mexicanos en esos temas excede los límites del presente artículo, por lo que hubo que adoptar un criterio para la selección y este fue centrarse en los que están directamente ligados con la firma del Tratado de Libre Comercio de América del Norte, entendido como consecuencia del fin de la guerra fría y la decisión estadounidense de favorecer la multiplicación de los intercambios económicos y adecuarse a las condiciones productivas que imponía la globalización, con el fin de mantener su posición hegemónica en el mercado mundial. A mi juicio, este fue el efecto de mayor trascendencia para México al finalizar el sistema bipolar.

La decisión no fue fácil porque implicó dejar fuera asuntos relevantes de la agenda bilateral México-Estados Unidos, el petróleo y el narcotráfico, que aparecen como tales desde los años setenta, cuando México regresa al mercado petrolero en calidad de exportador y Estados Unidos comienza a achacar el creciente consumo de drogas en su país a la producción mexicana de narcóticos. Periódicamente, uno y otro han dado origen a tensiones y desencuentros entre los dos países. En ambos casos, hemos visto una evolución muy importante que puede resumirse subrayando dos hechos que justifican el peso que tienen en los análisis de los especialistas. Estados Unidos, el principal importador de petróleo mexicano, ha reducido de manera drástica su dependencia del mercado externo al reanimar la industria petrolera local

${ }^{3}$ El esfuerzo por crear una asociación de estudiosos de la disciplina viene de tiempo atrás, de 1967, cuando Modesto Seara Vázquez creó un primer grupo de investigadores sobre las relaciones internacionales, el cual en 1982 se convirtió en la AMEI. 
y convertirse en uno de los principales productores de crudo en el mundo. Respecto al narcotráfico y las actividades delictivas de los grupos criminales vinculados con el trasiego de drogas a Estados Unidos, basta decir que se han convertido en un desafío al Estado mexicano, que ha perdido el control de partes del territorio y ha sido incapaz de encontrar la estrategia para asegurar la paz y la seguridad de los mexicanos.

Para elaborar este artículo se revisaron únicamente libros y revistas publicados en México por autores que forman parte de las instituciones que ofrecen los programas de posgrado mencionados párrafos atrás. Se hace referencia también a la revista del Instituto Matías Romero de Estudios Diplomáticos, de la Secretaría de Relaciones Exteriores, que difunde trabajos académicos y de miembros del servicio exterior mexicano, así como a documentos publicados por el Consejo Mexicano de Asuntos Internacionales (COMEXI), un think tank dedicado al análisis de las relaciones internacionales con el propósito de elaborar propuestas sobre la política exterior y otras políticas públicas de México.

\section{EL FIN DEL ORDEN INTERNACIONAL DE LA POSGUERRA}

La caída del muro de Berlín en noviembre de 1989 marcó de manera simbólica el inicio del proceso de desintegración del bloque de países encabezado por la URSS que culminó con la desaparición de la hasta entonces gran potencia. La guerra fría había terminado y el sistema bipolar de la posguerra desaparecido. El relanzamiento de la guerra fría por el presidente Ronald Reagan, en particular la Iniciativa de Defensa Estratégica-anunciada en marzo de $1983^{-}$que pretendía crear un paraguas antimisiles que protegiera el territorio estadounidense de un ataque nuclear, condujo a la aceptación por parte de los líderes soviéticos de la imposibilidad de continuar la carrera armamentista. Los problemas de la economía soviética eran más severos de lo que Occidente conjeturaba, por lo que el fin de la bipolaridad político-militar fue visto como un éxito rotundo de la -a partir de ese momento- potencia única.

Estos acontecimientos, que cambiaron la manera de entender las relaciones internacionales desde la segunda mitad de los años cuarenta, provocaron 
inquietud entre los especialistas mexicanos; era necesario reflexionar acerca de las consecuencias de la pérdida del factor de equilibrio que había impedido una conflagración como las dos vividas en la primera mitad del siglo xx. El pesimismo se expresó como el temor por el surgimiento de un orden militar dominado por Estados Unidos y apoyado por sus aliados y el Consejo de Seguridad de la onu, tal y como había ocurrido durante la guerra del Golfo Pérsico en agosto de 1990 (González Olvera, 199I). En el examen de la situación europea, el recelo por la reaparición de los nacionalismos en el Este tenía justificación. El ambiente de violencia en que se produjo la desintegración de Yugoslavia recordaba los momentos previos al estallido de la Primera Guerra Mundial, y era apenas el inicio de un proceso que dividiría a los principales Estados plurinacionales de Europa Central y del Este y conduciría a la desaparición de la URSS. El problema de las nacionalidades no había sido resuelto durante las décadas de regímenes de partido único, y el resurgimiento del nacionalismo anticipaba conflictos difíciles de vaticinar (Castro, 1994).

El triunfalismo con que en algunos países del otrora bloque occidental se recibió la caída del bloque soviético, llamaba a proceder con cautela. La tesis del fin de la historia de Francis Fukuyama fue tomada por algunos como una provocación que condujo a descalificaciones, pero también a reflexiones sobre el pensamiento político estadounidense después del desplome de la URSS y el socialismo real. La ideología que sustenta el modelo económico y político de EE. UU. había resultado triunfante, pero tenía la cara no del orden liberal propugnado, sino del neoconservadurismo (Orozco, I99I).

La bibliografía sobre el proceso vivido por la URSS a partir de la desaparición del bloque socialista permite comprender los efectos del proceso de reformas económica (perestroika) y política (glasnost) puesto en marcha por Mijail Gorbachov a partir de 1985, y la manera como Rusia se fue adaptando a su nueva condición. La Revista de Relaciones Internacionales de la Unam, del Centro de Relaciones Internacionales de la Facultad de Ciencias Políticas y Sociales, publicó en 1992 un número dedicado a analizar dicho proceso, titulado «De la desintegración de la URSS al surgimiento de la CEI». Está integrado por Is artículos de seis especialistas en los países socialistas que, en términos de Graciela Arroyo, coordinadora «del número, representan un esfuerzo de síntesis y reflexión sobre la perestroika, la disolución de la 
URSS y su "transfiguración en una incierta Comunidad de Estados Independientes» (Arroyo Pichardo, I992: 5). El resultado cumplió con el objetivo de organizar un cúmulo de información para ofrecer una visión general de la rápida transformación que se estaba viviendo: la perestroika, el fin de la guerra fría, las causas económicas y políticas de la desintegración de la URSS, el fallido golpe de Estado de agosto de i99i y la renuncia de Gorbachov a la presidencia del país en diciembre de ese mismo año, la fragmentación del poder militar soviético y los compromisos internacionales de la naciente Comunidad de Estados Independientes.

Los trabajos de Ana Teresa Gutiérrez del Cid en esa revista y en publicaciones de la UAM-X, su institución de adscripción, permiten hacer un seguimiento de los retos que ha enfrentado Rusia en el transcurso de las tres últimas décadas. La estrategia de la política exterior soviética cambiaría por lo que era importante explicar el viraje, «la nueva mentalidad», que guiaba la política exterior soviética (Gutiérrez del Cid, 1990). Las reformas económica y política (Gutiérrez del Cid, I99ra), las consecuencias que pudieran haber provocado el desmembramiento de la URSS (Gutiérrez del Cid, I99ıb) y aspectos jurídicos involucrados en la creación de la Comunidad de Estados Independientes (Gutiérrez del Cid, 1992), se analizan en el momento en que provocaban todavía más preguntas que respuestas.

La apuesta por la recuperación de la industria petrolera para darle un papel estratégico en las relaciones exteriores del país (Gutiérrez del Cid, 2008), tenía que ver con las relaciones europeas. La preocupación de la Unión Europea por su seguridad energética funcionó a favor del diálogo y acercamiento con la URSS en la década de los ochenta. A pesar de las dudas y el riesgo que los críticos advierten en la dependencia energética de Alemania y Polonia, principalmente, al oleoducto ruso entonces construido se han sumado nuevos proyectos que aseguran la exportación de crudo y gas rusos a la ue (Gutiérrez del Cid, 20Io)

El seguimiento de las acciones de Vladimir Putin desde su llegada al poder en 1999 ha permitido identificar el proyecto ruso para posicionarse entre el pequeño grupo de potencias con capacidad de influir en la política mundial (Gutiérrez del Cid, 2009). Los profesores de la UAM-X que abordan el estudio de las relaciones internacionales desde la perspectiva teórica de la geopolítica realizan un trabajo de seguimiento puntual sobre el proceso de 
formación de un nuevo orden interestatal mundial distinto al que se vislumbraba en el momento de la caída de la URSS y la desaparición del bloque socialista. El estudio del papel de EE. UU., Rusia y China en la reconstrucción de ese orden (Gutiérrez del Cid, Pérez Gavilán, Pérez Rodríguez, 20I5), los escenarios posibles para México en el reordenamiento mundial (Arroyo Velasco y Valdivia, 20Io), los escenarios de las relaciones entre Asia Central y México (Arroyo Velasco, 2009), entre otros, les permiten trazar el mapa de una geopolítica del siglo XXI (Pérez Gavilán, 20I7), en la cual Rusia regresa con el rol estelar de potencia global (Gutiérrez del Cid, 2017).

\section{GLOBALIZACIÓN, BLOQUES REGIONALES Y AGENDA GLOBAL}

El nuevo orden interestatal mundial que establezca un equilibrio de poder sustitutivo al sistema bipolar no cobra forma aún, más de 30 ańos después de la caída del muro de Berlín. La incertidumbre provocada por la posición de EE. UU. como potencia única, hegemónica a nivel mundial, con capacidad para hacer prevalecer sus criterios frente a la postura del resto de la sociedad interestatal (Ojeda, I99I), provocó que buena parte de la reflexión de los internacionalistas se centrara en las consecuencias que este hecho tendría para México, de las vulnerabilidades que deberían atenderse y de las oportunidades que se abrían ante la posibilidad de una etapa de paz y prosperidad ante la desaparición de la amenaza militar que gravitó sobre el mundo durante la guerra fría. Esta tendencia se definió mejor cuando el gobierno mexicano aceptó la proposición, hasta entonces parcial e imprecisa que Estados Unidos había avanzado en algunos momentos durante la administración de Ronald Reagan y en la campaña presidencial de George Bush, de iniciar la formalización de un proyecto de integración norteamericano. La decisión de abrir las negociaciones de un acuerdo de libre comercio entre México y Estados Unidos, y la decisión de Canadá de renunciar al previamente firmado con Estados Unidos para discutir un acuerdo trilateral, orientó las prioridades de investigación. Los acuerdos comerciales bilaterales de Estados Unidos-Canadá y Estados Unidos-México firmados durante el gobierno de Ronald Reagan fueron objeto, a finales de los años ochenta, de trabajos escritos principalmente por economistas y especialistas en relaciones 
internacionales que anticiparon el proceso de integración de México con Estados Unidos, como Pedro F. Castro Martínez, en la UAM-I (Castro Martínez, I989b; Castro Martínez, I990) y Gustavo Vega Cánovas en el Colmex, como se puede leer en una antología de sus escritos publicada hace algunos ańos (Vega Cánovas, 20I4).

El inicio de las negociaciones entre los tres países en junio de I99I hizo que buena parte de la discusión en congresos, seminarios, mesas redondas y eventos académicos se centrara en el acuerdo que implicaba un viraje en la política exterior tradicional de México, defensiva y cautelosa, marcada en los años inmediatamente anteriores por tensiones, fricciones y desacuerdos derivados de la vecindad geográfica con EE. UU. y de las visiones opuestas sobre temas de política regional en el continente americano. Hubo que enfrentar la desconfianza hacia el país vecino que compartían muchos mexicanos, pero también la inseguridad del sector empresarial ante la magnitud percibida del reto de la integración trilateral, por lo que desde el gobierno se trabajó para persuadir a los actores económicos y la opinión pública en general de que México estaba ante una oportunidad. Para ello, se incluyó a los organismos empresariales en la negociación, la que «aportó opiniones, aseguró consensos y estableció conexiones con sus similares de los otros dos países» (Puga, 2004: 248). A partir de esta experiencia, los documentos de análisis elaborados para expresar puntos de vista particulares -como en los casos de COMEXI, México Evalúa o CIDAC- sobre las relaciones de México con el exterior, han robustecido la discusión sobre temas relevantes de política económica internacional y del papel de México en el escenario mundial. La respuesta a estos planteamientos se ha dado no solo en el ámbito académico, sino de organizaciones de la sociedad civil como la Red Mexicana de Acción frente al Libre Comercio.

La intención de abrir las negociaciones para la creación del área de libre comercio en el norte del continente condujo de manera inmediata a reflexionar acerca de los cambios inevitables en la política exterior mexicana (Roldán, 1990; Ortiz, 1990). Tendrían que definirse las directrices a seguir en la etapa de cooperación que se abría con Estados Unidos y Canadá, así como establecer los objetivos y estrategias dirigidas a otros países y regiones que habían ocupado un lugar dentro del esquema de diversificación de las relaciones económicas desde los años setenta (Del Alizal, 1992). 
Canadá se convirtió en un tema de investigación relevante. Hasta pocos años antes se le veía en la literatura de la disciplina como una posibilidad a explorar con el propósito de diversificar las relaciones exteriores de México, sobre todo a partir de experiencias como el acuerdo migratorio bilateral firmado en 1974 y la organización conjunta de la reunión de Cancún sobre el Diálogo Norte-Sur en 198I. Era necesario conocer al tercer socio del tratado en proceso de negociación, su historia, vida política, las características de su economía, sus políticas de comercio e inversión, su política exterior y, no menos importante, el acuerdo bilateral de libre comercio en vigor con EE. UU., al cual renunciaba para sumarse a la negociación del tratado trilateral. En publicaciones de distintas instituciones comenzaron a aparecer artículos y libros que explicaban aspectos relevantes sobre estos temas (Castro Martínez, I989a; Del Alizal, I99I; Jaime, I99I; Rosas, I993; Castro Martínez, I994a; Castro Martínez, I994b). La necesidad de conocer la realidad canadiense se manifiesta en hechos como el que la prestigiada revista Comercio Exterior publicara en 1994 dos números monográficos sobre Canadá, coordinados por Pedro Fernando Castro Martínez, y que el Centro de Investigaciones sobre Estados Unidos de la Unam, fundado en 1989, se transformara en el Centro de Investigaciones sobre América del Norte (CISAN) para incorporar a sus labores el estudio de Canadá. Este centro de investigación responsable de la revista Norteamérica es una referencia en México para los interesados en análisis sobre política interna y exterior de esos los países del norte.

A partir de la entrada en vigor del Tratado de Libre Comercio de América del Norte (TLCAN) el I de enero de I994, aparecen publicaciones sobre el documento ratificado por los poderes legislativos de los tres países signatarios, incluidos los acuerdos de cooperación ambiental, laboral y de solución de controversias conocidos como «acuerdos paralelos», que fueron ańadidos por el Congreso de Estados Unidos para ratificar el texto firmado por los presidentes de México y Estados Unidos y el primer ministro de Canadá en diciembre de 1992 (Emmerich, 1994; Bernal, 1994; Vega Cánovas, 2005), pero un aspecto a subrayar es que para entonces se percibe con claridad que las relaciones en América del Norte tendrían que analizarse de manera integral, no solamente desde el punto de vista del TLCAN. La revisión de enfoques teóricos sobre la integración económica, formación de regiones económicas e interdependencia en la etapa de la globalización, apareció en publicaciones 
académicas, al igual que el interés por conocer las visiones prevalecientes en los ahora socios sobre el cuidado del medio ambiente, la percepción de mexicanos y estadounidenses sobre un tratado como el que se había formalizado, la importancia de la reforma educativa en el nuevo contexto y el impacto sectorial en la industria manufacturera mexicana (Morales Aragón y Dávila Pérez, 1994). La «nueva agenda bilateral México-Estados Unidos» (Verea, Fernández de Castro y Weintraub, 1998) incluye de manera destacada el aspecto central para el proceso de integración dada la complementariedad de los mercados laborales: la migración.

Los estudios sobre el TLCAN, sus resultados y los aspectos que podrían modificarse para cumplir con los objetivos o expectativas originalmente planteados, han sido elaborados periódicamente desde diferentes perspectivas teóricas y énfasis disciplinarios (Vega Cánovas, 20ıо; Briseño y Castillo, 20II; Oropeza, 20I4; Calderón, 20I9; Toro, 2020). Por esta razón, cuando el candidato a la presidencia de Estados Unidos por el Partido Republicano, Donald Trump, amagó con poner fin al "peor tratado firmado por el país», se entendió como parte de un discurso dirigido a sus potenciales electores. El problema fue cuando llegó a la presidencia y aplicó medidas proteccionistas en contra de México y Canadá. La necesaria actualización del TLCAN, reconocida y hasta esperada por analistas de los tres países, se hizo bajo presión y atendiendo solo los intereses de Estados Unidos, que se propuso «rebalancear el acuerdo a su favor, reducir el déficit comercial, recuperar empleos en la manufactura y desincentivar las inversiones productivas en México» (De la Mora, 2019: 978).

\section{POLÍTICA EXTERIOR MEXICANA}

La política exterior mexicana es objeto de un análisis sistemático por lo menos desde los años setenta. En el periodo que abarca este trabajo dicho examen adquirió una peculiaridad: la elaboración de balances sexenales que se justifican en la posibilidad de tener una perspectiva de mediano plazo sobre los objetivos planteados al inicio de la gestión y los logros obtenidos al final de la misma. La obligación constitucional, a partir de 1983, de presentar el Plan Nacional de Desarrollo y los planes sectoriales que de él se derivan ayudó 
a contar con un documento en el que se definen las prioridades de la acción gubernamental en materia de política exterior. Otro aspecto interesante de este tipo de ejercicio es que permite reconocer la disposición del carácter del presidente en turno, un aspecto a considerar en la política exterior dada la especificidad de que su conducción se reserva al presidente de la República (art. 89, fracción X de la Constitución) quien, en su calidad de autoridad de mayor jerarquía en el país, tiene el derecho exclusivo de decidir en nombre de los mexicanos y adquirir compromisos frente a la sociedad internacional.

En la UAM-I la idea de realizar un balance del sexenio surgió en la Coordinación de Ciencia Política, y tomó forma en el coloquio que con ese nombre se llevó a cabo en noviembre de 1988, que tuvo como objeto analizar las políticas públicas en el sexenio de Miguel de la Madrid. En el evento participaron profesores de distintas disciplinas e instituciones y en Iztapalapa, la revista de la División de Ciencias Sociales y Humanidades, se publicaron algunas de las ponencias presentadas. A partir de esa fecha, los eventos se han repetido (Méndez y Leyva, 2007; Valdés, María Eugenia, 2012) aunque en el gobierno del presidente Carlos Salinas el estudio se hizo a mitad del sexenio debido a la importancia de los cambios que se realizaron a lo largo de los tres primeros años de la administración (Castro Martínez, 1992). En todas las publicaciones se incluye por lo menos un artículo sobre la política exterior.

En el Colmex los análisis sexenales fueron una iniciativa de Humberto Garza Elizondo y fruto de un seminario sobre política internacional a cargo del Centro de Estudios Internacionales (CEI). Inició, al igual que en la UAM-I, con el examen de la política exterior durante el periodo I982-I988, y los trabajos presentados formaron parte de un número especial de Foro Internacional, la revista del CEI. La característica de la publicación fue la inclusión de colaboraciones de funcionarios públicos junto a las de académicos (Foro Internacional, 1990). A partir de entonces, se ha publicado cada fin de sexenio un número especial que reúne análisis de especialistas en las relaciones internacionales del país que analizan los temas principales y las relaciones con países y regiones de interés para la política exterior mexicana (Foro Internacional, 1994; Foro Internacional, 2001; Foro Internacional, 2008; Foro Internacional, 2013; Foro Internacional, 2019). Investigadores como Olga Pellicer, Blanca Torres, Ana Covarrubias, Lorena Ruano, Gustavo Vega, Jorge Schiavon, Rafael Velázquez, Guadalupe González, Luz María de la Mora, 
Jorge Durand, Reynaldo Ortega, Carlos Uscanga, Arturo Santacruz, Marta Tawil, Hilda Varela, Romer Cornejo, Susana Chacón, Jorge Chabat, Ricardo Macouzet, Raúl Benítez Manaut, Pedro F. Castro y José Luis Piñeiro han colaborado a lo largo de los 30 años transcurridos desde la aparición del primer balance sexenal. Es evidente que estos análisis de mediano plazo han resultado atractivos a los lectores y un buen apoyo a la docencia.

Durante los últimos tres lustros han surgido estudios que emplean enfoques hasta ese momento poco utilizados para analizar la política exterior mexicana. El proyecto de investigación «México, las Américas y el Mundo», a cargo de profesores de la División de Estudios Internacionales (DEI) del Cide, inició en 2004 con el objetivo de conocer las percepciones de los mexicanos respecto a la política exterior y las relaciones internacionales. A lo largo de io años realizó encuestas periódicas (cada dos años) entre la población general y líderes de opinión del sector académico, empresarial y organizaciones de la sociedad civil para conocer sus «opiniones, actitudes, evaluaciones, creencias, intereses, aspiraciones, sentimientos, valores sociales y conductas... respecto a asuntos internacionales» (Maldonado et. al, 20I6: 5). Los hallazgos son sugestivos y muestran coincidencias y diferencias en las percepciones de la población general y los líderes que pueden ayudar a los tomadores de decisiones, pero también a quienes analizan la política exterior mexicana con otros fines (Schiavon, 2008; Schiavon, 20Iob; Schiavon y Alberro, 20I0c; Schiavon y Velázquez Flores, 20I2; Schiavon, 20I3).

Consuelo Dávila, Jorge A. Schiavon y Rafael Velázquez Flores coordinaron un libro sobre la diplomacia local en México publicado en 2008. Como ellos señalan en la introducción, la poca importancia que se había dado al estudio de las relaciones exteriores de las entidades federativas obedeció a los rasgos característicos del sistema político mexicano que dejaba poco espacio de acción a los gobernadores para promover acciones internacionales. Hasta ese momento identifican solo tres estudios previos sobre el tema, el pionero escrito por Schiavon. La hipótesis general que guía la investigación es que la globalización genera oportunidades a las entidades federativas para promover intereses locales, las cuales pueden aprovecharse debido a la mayor autonomía de que gozan las entidades, debido a los efectos de medidas ligadas a la democratización del país. El aumento en los márgenes de maniobra permitirá a los gobiernos estatales y municipales promover ac- 
ciones de promoción turística, de la inversión extranjera directa y en temas migratorios, entre otros. El resultado del proyecto fueron I4 trabajos en los que se presentan los aspectos teóricos de la diplomacia local, el marco jurídico en que se desenvuelve la participación de las entidades federativas en el exterior y la actuación de gobiernos de las regiones norte, centro y sur-sureste (Dávila, Schiavon y Velázquez, 2008). Como investigador del Cide, Jorge Schiavon ha seguido trabajando sobre el tema de la diplomacia local (Schiavon, 20IOa; Schiavon, 20I5; Schiavon y González, 20I8). A doce años de distancia de la aparición de la primera publicación, la Universidad de Guadalajara ofrece un programa nuevo de maestría con este enfoque de las relaciones internacionales.

Un tercer enfoque recientemente utilizado en el análisis de la política exterior mexicana es el papel que juega el poder legislativo en esa materia. Los poderes del legislativo están limitados por la facultad constitucional del presidente de la república para conducir la política exterior. A esta cuestión, que deriva del marco jurídico, se añade la del funcionamiento del sistema político. Durante décadas, el Partido Revolucionario Institucional (PRI) detentó la mayoría en el Congreso de la Unión que hizo irrelevante la discusión de las iniciativas y acciones del gobierno encabezado por el presidente, el jefe real de ese partido. Cuando se produjo la alternancia en el poder y se aprobaron reformas para aumentar las competencias del legislativo en materia de las relaciones con el exterior, pudo darse seguimiento al debate de algunas iniciativas, con lo cual se amplió el examen de los puntos de vista de los partidos políticos sobre las acciones del ejecutivo (Del Alizal y López Sánchez, 2013; Del Alizal y Rubio, 2014; Del Alizal, 2015).

Las relaciones bilaterales México-Estados Unidos es el tema sobre el cual más se ha escrito durante las últimas tres décadas. Su fortalecimiento a partir de la apertura de negociaciones del tLCan y hasta la llegada de Donald Trump a la Casa Blanca en enero de 20I7, así como la complejidad de una agenda bilateral de países fronterizos, separados por una enorme desigualdad económica-social, pero inmersos en una intensa red de intercambios de todo tipo, explican este hecho. La ruptura del entendimiento que había prevalecido pudo salvarse debido a la institucionalización alcanzada en décadas anteriores, la cual hizo posible que el trabajo cotidiano se atendiera por personal especializado de diferentes dependencias de ambos gobiernos; los aspectos 
conflictivos se resolvieron bajo presión, con amenazas, en el estilo impuesto por el presidente estadounidense, tal y como se dio la renegociación del TLCAN y se trató el tema de la migración, no solo mediante la construcción de un muro fronterizo, sino dando al gobierno mexicano el papel de receptor de los solicitantes de asilo en EE. UU. - «tercer país seguro»- y dique de los migrantes centroamericanos.

\section{LA MIGRACIÓN: EL TEMA PENDIENTE}

La migración mexicana a Estados Unidos es probablemente el asunto más estudiado de las relaciones bilaterales, sobre el cual, desde distintas disciplinas de las ciencias sociales y las humanidades, se han generado aportaciones al conocimiento de un fenómeno de importancia central para México. En las principales universidades y centros de investigación del país, nacionales o estatales, hay proyectos que lo abordan. Algunas de esas instituciones cuentan además con programas de posgrado sobre población en donde demógrafos, economistas y sociólogos han desarrollado estudios sistemáticos sobre el tema. En la UAM-I, profesores de distintos departamentos tienen abierta una línea de investigación sobre migración: antropólogos, economistas, geógrafos, internacionalistas, politólogos y sociólogos del trabajo abordan perspectivas diferentes del problema, lo cual ha derivado en una producción abundante y rica por la diversidad de enfoques utilizados para su estudio.

El interés por la migración mexicana a Estados Unidos también ha quedado plasmado en tesis de maestría y doctorado de los posgrados de las disciplinas correspondientes, como el Posgrado en Estudios Sociales, en sus líneas de conocimiento en Estudios Laborales y Procesos Políticos, en donde Fernando Francisco Herrera Lima, profesor que ha estudiado el tema desde tiempo atrás (Herrera Lima y Macías, 1997; Herrera Lima, 2005; Herrera Lima, 20I2a; Herrera Lima, 20I2b; Herrera Lima, 20I4a; Herrera Lima, 20I4b), se ha desempeńado como director de la mayoría de esas tesis. En este mismo posgrado, Gustavo E. Emmerich abrió, antes de su prematura partida, una línea temática de investigación sobre el voto extraterritorial (Emmerich y Peraza, 20II; Emmerich, 20I3), bajo la cual se han elaborado tesis doctorales que han contribuido al conocimiento de los mexicanos en 
el extranjero desde la óptica de la ciencia política. Dos de estas tesis han sido publicadas debido al interés que despierta un tema todavía debatido, a pesar del tiempo transcurrido desde la primera elección en que los mexicanos votaron desde el extranjero (Muñoz Pedraza, 2016; Carrera Barroso, 2020). Los estudios pioneros en esta línea de investigación los escribió Leticia Calderón Chelius, del Instituto Mora, los cuales surgieron como una demanda de reconocimiento pleno a los derechos políticos de los mexicanos que viven fuera de las fronteras nacionales (Calderón Chelius, 2003, 2004, 20IO, 20I7) y se ha sostenido como un esfuerzo de reflexión de largo aliento sobre la noción de democracia en el país.

En algunas instituciones académicas en donde se estudian las relaciones internacionales se observa la relevancia del tema migratorio en el número de publicaciones de sus investigadores y la continuidad en el tiempo, lo que permite identificar las distintas olas migratorias que se han dado, los problemas que se han atendido mediante acciones del gobierno mexicano y los retos actuales. En el CISAN, la migración de mexicanos a Estados Unidos es una línea de investigación desarrollada desde la fundación del centro que, cuando se convierte en CISAN, ańade el estudio de la migración mexicana a Canadá (Verea Campos, 20I0, 20I4; Levine, Núńez y Verea Campos, 2016).

Una de las frustraciones que produjo el TLCAN fue que el acuerdo no contuvo, como esperaban sus promotores en EE. UU., el flujo de migrantes mexicanos indocumentados. Sin embargo, las estimaciones del Pew Research Center muestran que ese flujo sí se ha frenado. De acuerdo con sus estimaciones, en 2017 había menos de cinco millones de inmigrantes mexicanos no autorizados, los cuales representaron por primera vez menos del $50 \%$ del total de ese tipo de inmigrantes, al caer Io puntos porcentuales respecto al $57 \%$ que representaron en 2007, cuando empezó el declive (Pew Research Center, 2019).

Esta tendencia a la baja en la migración mexicana, acentuada por el endurecimiento de la política de deportación durante las administraciones de Barack Obama y Donald Trump, explica que ahora se preste más atención a la migración de retorno al país, los problemas derivados de la separación de familias migrantes, la migración de niños no acompañados provenientes de Centroamérica y, más recientemente, las caravanas de migrantes hondureños. Es decir, la frontera sur está reclamando el interés de los especialistas. 
Con información generada por la Encuesta sobre Migración en la Frontera Norte del Colef comenzaron a elaborarse trabajos sobre la migración nacional e internacional que se publicaron durante el periodo en revisión. María Eugenia Anguiano Téllez mostró la relación entre el crecimiento demográfico de la frontera norte y el dinamismo del mercado de trabajo, en momentos en que la economía regional crecía a un ritmo mayor que la del resto del país (Anguiano Téllez, 1998). Diez años más tarde, la misma investigadora publicaba los resultados de un primer acercamiento a lo que estaba ocurriendo en la frontera sur del país, en Chiapas específicamente, que es una entidad expulsora de migrantes hacia otras zonas del país y a EE. UU., pero también de tránsito y destino de quienes desde Centroamérica emprenden el viaje al norte del continente (Anguiano Téllez, 2008). En 2016 aparece un trabajo coordinado por ella y Daniel Villafuerte en donde se llama a la formulación de una política migratoria a partir de bases distintas a la mera detención de los migrantes en la frontera sur, para ofrecer una respuesta a la crisis humanitaria que se venía gestando con el creciente flujo de centroamericanos que buscaban llegar a EE. UU. cruzando el territorio mexicano, una travesía cada día más peligrosa en donde la violencia y la violación de los derechos humanos de los migrantes son constantes (Anguiano Téllez y Villafuerte, 2016). Sin embargo, a pesar de cambios en la legislación y política migratoria durante los gobiernos de Felipe Calderón y Enrique Peña Nieto, así como las recomendaciones de organismos internacionales para terminar con la violación de los derechos humanos de los migrantes, la situación se agravó hasta llegar al punto en que nos encontramos actualmente en que la Guardia Nacional está encargada de detener a los centroamericanos que buscan llegar a EE. UU.

Elaborar una propuesta de «desarrollo regional transfronterizo, sustentable, corresponsable y enfocado en la calidad de vida» en la frontera sur es el objetivo principal del proyecto de investigación Región Transfronteriza México-Guatemala en donde participan 90 investigadores del Centro de Investigación en Ciencias de la Información Geoespacial (Centro Geo), la DEI-Cide, el Colef, el Centro de Investigaciones y Estudios Superiores en Antropología Social (CIESAS), el Instituto Mora, El Colegio de la Frontera Sur (eCOSUR), la Facultad Latinoamericana de Ciencias Sociales (FLACSO) sede Guatemala y la Universidad de San Carlos, Guatemala. La suma de 
capacidades y recursos que representa demuestra la magnitud del reto que se enfrenta en la zona fronteriza. Por eso es importante destacar que la perspectiva del proyecto es proporcionar información y análisis útiles para diseñar «acciones de política pública e iniciativas sociales». El investigador responsable del proyecto por parte del Cide es Carlos Heredia (Heredia, 20I6, 2019, 2020; Heredia y Durand, 2018).

\section{CONSIDERACIONES FINALES}

El peso de las relaciones México-Estados Unidos en los estudios de relaciones internacionales en el país es evidente. Sin embargo, dista de cohibir el abordaje de otras temáticas de las relaciones exteriores del país. En estos momentos en que la pandemia del Covid i9 coloca en un lugar central la reflexión de hacia dónde deberán encaminarse las acciones de Estados, organizaciones interestatales y de la sociedad civil para analizar sus efectos en la vida económica, política, social y personal de millones de seres humanos en el mundo, la cooperación internacional aparece como un camino a transitar para impedir que las potencias en busca de un reacomodo en la distribución del poder en la etapa de la pospandemia, sofoquen y manipulen las demandas y necesidades de los países que dependen de la cooperación para hacer frente a los retos mundiales del siglo XXI.

Los efectos de una interconexión cada día más estrecha propiciada por los medios de transporte y comunicación actuales, así como la multiplicación de los intercambios y la movilidad internacional, han traído beneficios, pero también consecuencias negativas, sobre todo para las personas que han quedado al margen del crecimiento económico y los avances del bienestar social durante la etapa de la globalización. La ONU, los organismos especializados que de ella dependen, así como otras organizaciones ligadas a la cooperación internacional, son la parte que sobrevive del orden internacional creado a finales de la segunda guerra mundial. Habrá que aprovechar su experiencia y mejorar su efectividad frente a las decisiones de los Estados más fuertes para entrar en la etapa de la pospandemia. 


\section{REFERENCIAS}

Anguiano Téllez, M.E. (1998). Migración a la frontera norte de México y su relación con el mercado de trabajo regional, Papeles de Población, vol. 4, núm. I7, julio-septiembre, 65-79.

Anguiano Téllez, M.E. (2008). Inmigración, emigración y tránsito migratorio en Chiapas: un bosquejo general, LiminaR, vol. 6, núm. 2, diciembre.

Anguiano Téllez, M.E. y Cruz Piñeiro, R. (coords., 20I3). Migraciones internacionales, crisis y vulnerabilidades. Perspectivas comparadas. Tijuana, Baja California, El Colegio de la Frontera Norte. Anguiano Téllez, M.E. y Villafuerte Solís, D. (coords., 20I6). Migraciones en tránsito a Estados Unidos: vulnerabilidades, riesgos y resiliencia. Tijuana-Tuxtla Gutiérrez-San Cristóbal de las Casas, El Colegio de la Frontera Norte-Universidad de Ciencias y Artes de Chiapas-Centro de Estudios Superiores de México y Centroamérica. Arroyo Pichardo, G. (1992). Presentación. Revista de Relaciones Internacionales de la Unam, núm. 54, 5-7.

Arroyo Velasco, R. (coord., 20Io). México ante el nuevo orden internacional: los escenarios, México: UAM-X, CSH.

Arroyo Velasco, R. (coord., 2009). Nuevos escenarios geopoliticos. Asia Central-México, México: Uam.

Briseño, J. y Castillo, O. (20II). Repatriación de utilidades de la inversión extranjera directa: la relación entre México y Estados Unidos, Norteamérica, Año 6, núm. I, I27-I66.

Beck, U. (1992), Risk Society: Towards a New Modernity. London: Sage.

Beck, U. (2007). La sociedad del riesgo mundial: en busca de la seguridad perdida. Barcelona: Paidós.

Calderón, C. (2019). TLCAN a 24 años de su existencia: retos y perspectivas. México: El Colegio de la Frontera Norte, Universidad Panamericana/EÓN.

Calderón Chelius, L. (2003). Votar en la distancia. La extensión de los derechos politicos a los migrantes, experiencias comparadas. México: Instituto de Investigaciones José María Luis Mora. 
Calderón Chelius, L. (2004). La nostalgia como poder político. Aproximaciones metodológicas para el estudio del ejercicio político de los migrantes, Enfoques: Ciencia Politica y Administración Pública, núm. 3, 35-54.

Calderón Chelius, L. (2010). Los superhéroes no existen. Los migrantes mexicanos ante las primeras elecciones en el exterior. México: Instituto de Investigaciones José María Luis Mora.

Calderón Chelius, L. (20I7). Avances en la implementación del voto extraterritorial mexicano: entre dudas y certezas. América Latina Hoy, vol. 76, 75-92.

Carrera, J.A. (2020). Gobernanza electoral y voto extraterritorial en México, 2005-2018. Guanajuato: Instituto Electoral del Estado de Guanajuato.

Castro Martínez, P.F. (1989a). El Acuerdo de Libre Comercio Estados Unidos-Canadá. Comercio Exterior. Revista del Banco Nacional de Comercio Exterior, vol. 39, núm. 4.

Castro Martínez, P.F. (1989b). México a la hora de la integración. Iztapalapa: Revista de Ciencias Sociales y Humanidades, Año 9, núm. I8, julio-diciembre, 55-65.

Castro Martínez, P.F. (1990). México y la política comercial estadunidense, 1982-1988. Foro Internacional, vol. Xxx, núm. 3(II9), 48I-496.

Castro Martínez, P.F. (1992a). ¿Nuevo separatismo de Quebec? Foro Internacional, vol. 32, núm. 4 (I28-I29), octubre-diciembre.

Castro Martínez, P.F. (I992b) El petróleo de México en la coyuntura del TLC. Iztapalapa: Revista de Ciencias Sociales y Humanidades, año I2, núm. 27, extraordinario.

Castro Martínez, P.F. (1993). Comercio e Inversiones México-Canadá: un asunto trilateral. Comercio Exterior. Revista del Banco Nacional de Comercio Exterior, vol. 43, núm. 5.

Castro Martínez, P.F. (I994a). México y Canadá: la búsqueda de una nueva relación. Foro Internacional: Revista trimestral de El Colegio de México, vol. xxxiv, núm. 4 (I38), octubre-diciembre.

Castro Martínez, P.F. (I994b). El nacionalismo esteuropeo: ¿̧ha terminado la caída? Polis 93: Anuario de Sociología. México, UAM-I. 
Castro Martínez, P.F. (1994c). Relaciones México-Canadá: un asunto de seguridad nacional. Sociológica: Revista del Departamento de Sociología, uAm-Azcapotzalco. Año 9, núm. 25, Especial Seguridad y Soberanía Nacionales en América Latina.

Dávila, C., Schiavon, J.A. y Velázquez Flores, R. (2008). Diplomacia local, relaciones internacionales de las entidades federativas mexicanas. México: Unam, Secretaría de Desarrollo Institucional, DGPyFE.

Del Alizal, L. (1989), De la planificación a la ejecución. Las relaciones bilaterales durante el sexenio i982-I988. Iztapalapa, año 9, núm. I8, extraordinario, 35-47.

Del Alizal, L. (199I). México y Canadá: ¿políticas exteriores convergentes? Polis, 9I. Anuario de Sociología. México: UAM-I, 35-48.

Del Alizal, L. (1992). Una política exterior de transición. En Castro Martínez, Pedro F. (coord.). Las politicas salinistas. Balance a mitad de sexenio. México: UAM-I, 35-54.

Del Alizal, L. (1993). Los acuerdos en materia ambiental y laboral del Tratado de Libre Comercio. Omnia, año 9, núm. 27, 47-52.

Del Alizal, L. y López Sánchez, É. (2013). La política exterior en el sistema político actual. En Escamilla Cadena, A. y Becerra Chávez, P. (coords.). El presidencialismo mexicano durante los gobiernos de la alternancia. México: Miguel Ángel Porrúa, UAMI, 25I-27I.

Del Alizal, L. y Rubio Jardón, N. (20I4). El papel del Congreso de la Unión en la política exterior: la discusión de la Iniciativa Mérida. Hernández de Gante, A., Gimate-Welsh, A. y Moreno Sánchez, C. La revitalización del Poder Legislativo en el gobierno calderonista. México: Gernika, BUAP, 25-66.

Del Alizal, L. (20I5). México: veinte años del Tratado de Libre Comercio de América del Norte. Relaciones entre poderes del Estado: acuerdos $y$ divergencias. Barcelona: Anthropos, UAM-I, 55-69.

De la Mora, L.M. (20I9). La política comercial de México durante el gobierno del presidente Enrique Peña Nieto. Foro Internacional, vol. Lix, núm. 3-4 (237-238), 957-987.

Emmerich, G.E. y Peraza, X. (20II). Sufragio transnacional. Experiencias latinoamericanas de voto desde el extranjero y de voto de los extranjeros. Emmerich, G. E. y Pries, L. (coords.). La trans- 
nacionalización. Enfoques teóricos y empiricos. México: Miguel Ángel Porrúa, UAM.

Emmerich, G.E. (2013). Sufragio transnacional: el voto de los mexicanos desde el extranjero. Revista Mexicana de Estudios Electorales, núm. I2.

Garza, H. et. al. (I990), Foro Internacional, vol. xxx, núm. 3(II9), enero-marzo.

Garza, H. et. al. (1994), Foro Internacional, vol. xxxıv, núm. 4(138), octubre-diciembre.

Garza, H. et. al. (200I), Foro Internacional, vol. XLI, 4(I66), octubre-diciembre.

Garza, H. et. al. (2013), Foro Internacional, vol. LIII, 3-4(2I3-2I4), julio-diciembre.

Garza, H. et. al. (20I9), Foro Internacional, vol. LIX, 3-4(237-238), julio-diciembre.

Giddens, A. (1999). La tercera vía, Madrid: Taurus.

Giddens, A. (2000), Un mundo desbocado. Los efectos de la globalización en nuestras vidas. Madrid: Taurus.

Giddens, A. (200I), La tercera vía y sus críticos. Madrid: Taurus.

González Olvera, P. (I99I), Notas sobre la gestación de un nuevo orden internacional. Revista de Relaciones Internacionales de la Unam, núm. 52, I5-I7.

Gutiérrez del Cid, A.T. (1990). La Casa Común Europea: parte esencial de la nueva mentalidad de la política exterior soviética. Revista de Relaciones Internacionales de la Unam, núm. 49, I27-I29.

Gutiérrez del Cid, A.T. (I99I). El proceso de reestructuración soviética. Argumentos. Estudios Críticos de la Sociedad, núm. I2, IOI-I24.

Gutiérrez del Cid, A.T. (I992a). Algunas reflexiones sobre las causas económicas y políticas de la desintegración de la URss. Revista de Relaciones Internacionales de la Unam, núm. 54, 23-30.

Gutiérrez del Cid, A.T. (1992b). El factor jurídico en la transformación de la Unión Soviética a la Comunidad de Estados Independientes. Argumentos, Estudios Críticos de la Sociedad, núm. I6-17, I34-136. Gutiérrez del Cid, A.T. (2008). El rescate de la industria petrolera en Rusia y la utilización de los energéticos como instrumento de 
política exterior. Argumentos: Estudios Críticos de la Sociedad, núm. 58, I37-I56.

Gutiérrez del Cid, A.T. (20Io). La seguridad energética de la Unión Europea en el contexto del reposicionamiento geopolítico de Rusia. Revista Mexicana de Política Exterior, núm. 89, 83-I22.

Gutiérrez del Cid, A.T. (2009). El ascenso de Rusia en el nuevo orden geopolítico mundial Denarius, núm. I9, I3-4I.

Gutiérrez del Cid, A.T., Pérez Gavilán, G. y Pérez Rodríguez, B. (2015). Las grandes potencias en la reconfiguración del nuevo orden mundial México: UAM.

Heredia, C. (20i6). Estados Unidos, México y el triángulo del norte centroamericano: ¿de la migración forzada a la movilidad laboral concertada? El sistema migratorio mesoamericano. México: El Colegio de la Frontera Norte, Centro de Investigación y Docencia Económicas.

Heredia, C. y Durand, J. (20I8). Los migrantes, los gobiernos y la sociedad civil en el sistema migratorio norte-mesoamericano. DPM 06. México: Cide, MIG.

Heredia, C. (2019). Economía política del desarrollo en Centroamérica. México y Centroamérica: encuentro postergado. México: COMEXI. Heredia, C. (2020). Las políticas de la administración Trump hacia México y su impacto en Centroamérica. Geopolitica en los tiempos de Trump: politica internacional y aspectos institucionales de la relación México-Guatemala. México: Centro Geo, Cide, CIESAS, Colef, Ecosur, Instituto Mora, Conacyt, 23-48.

Herrera Lima, F.F. y Macías, S. (1997). Migración laboral internacional: transnacionalidad del espacio social. UAP.

Herrera Lima, F.F. (2005). Vidas itinerantes en un espacio laboral transnacional. UAM.

Herrera Lima, F.F. (20I2a). La migración a Estados Unidos: una visión del primer decenio del siglo xxi. Norteamérica, Año 7, núm. 2, I7I-I97.

Herrera Lima, F.F. (20I4b). Las múltiples y diversas migraciones de México a los Estados Unidos: desempeños diferenciados en los mercados de trabajo norteamericanos. Patricia Galeana (coord.). 
Historia comparada de las migraciones en América Latina. México: Unam, IPGH, 459-485.

Herrera Lima, F.F., Massieu, Y., Ortiz Marín, C. y Revilla, U. (20I4a). Migración, trabajo y campesinado en la agricultura globalizada de México y Estados Unidos. En Hernández Romo, M. (coord.). Los nuevos estudios laborales en México. México: Miguel Ángel Porrúa, UAM-I, I63-200.

Herrera Lima, F.F. (20I2b). Las remesas: elemento fundamental del mercado de trabajo transnacional México-Estados Unidos. En Bouzas, J. A. (coord.). Trabajo y tecnología: cambios estructurales de la economía abierta. México: Unam.

Herrera Lima, F.F. (coord., 20I2c). Ser migrante latinoamericano, ser vulnerable, trabajar precariament., Barcelona: Antrophos, UAM- I.

Jaime, E. (I99I). México frente al Acuerdo de Libre Comercio. Revista Mexicana de Politica Exterior, núm. 30, 8-I4.

Levine, E., Núñez, S. y Verea, M. (2016). Nuevas experiencias de migración de retorno. México: CISAN, Unam, Instituto Matías Romero, SRE, Metropolis International.

Maldonado, G. et. al. (2016). Mexico, the Americas, and the World, 200420I4: Ten Years of Public Opinion on Foreign Policy. México: Cide, DTEI-257.

Méndez, L.H. y Leyva, M.A. (coords., 2007). 2000-2006. Reflexiones acerca de un sexenio conflictivo. 2 tomos. México: Eón Ciencias Sociales, UAM-A, UAM-I.

Morales Aragón, E. y Dávila Pérez, C. (1994). La nueva relación de México con América del Norte. México: Unam, FCPys, FE, DGAPA.

Muñoz Pedraza, A. (2016). Decidir desde Tierra Lejana. El voto de los mexicanos residentes en el extranjero. Los casos de Michoacán, Ciudad de México y Chiapas. Guanajuato, México: Instituto Electoral del Estado de Guanajuato.

Ochoa Bilbao, L. (20II), La carrera de relaciones internacionales en México: Orígenes y situación actual. México: El Colegio de México. doi: $<$ IO.2307/j.ctvhnobcd $>$. Fecha de consulta: 23 de marzo de $202 \mathrm{I}$. 
Ojeda, M. (20II). Prólogo. La carrera de relaciones internacionales en México: orígenes y situación actual. CDMX: El Colegio de México. 23 de marzo de 202I: doi: <IO.2307/j.ctvhnobcd >.

Ojeda, M. (199I). América Latina ante una nueva agenda internacional. Foro Internacional, vol. XXXII-I (I25), julio-septiembre, 7-I6.

Oropeza, A. (coord., 20I4). TLCAN: 20 años. ¿Celebración, desencanto $o$ replanteamiento? México: Unam-IIJ.

Orozco, J.L. (I99I). En torno al nuevo milenio liberal. Revista de Relaciones Internacionales de la Unam, núm. 50, 5-I9.

Ortiz, É. (1990). México y el Mercado Común Norteamericano: ¿integración silenciosa o concertada? Revista de Relaciones Internacionales de la Unam, núm. 47, 8I-90.

Pérez Gavilán, G. (coord., 20I7). La geopolitica del siglo XXI. México: UAM-X, CSH.

Puga, C. (2004). Los empresarios organizados y el Tratado de Libre Comercio de América del Norte. México: Miguel Ángel Porrúa, Unam.

Puga, C. (2012), Las ciencias sociales mexicanas en la primera década del siglo Xxi. Polis: Investigación y Análisis Sociopolitico y Psicosocial, vol. 8, núm. 2, I9-39.

Roldán, E. (1990). Una nueva política exterior. Los intereses de México: áreas y temas prioritarios. Revista de Relaciones Internacionales de la Unam, núm. 48, 57-60.

Rosas, M.C. (1993). El TLC entre México, Estados Unidos y Canadá: semejanzas y diferencias con el ALC entre Canadá y Estados Unidos Revista de Relaciones Internacionales de la Unam, núm. 57, 55-62.

Schiavon, J. (2008). Opinión pública, preferencias y política exterior: México ante el mundo. Foro Internacional, vol. XLV, núms. I-2 (I9I-I92), 35-65.

Schiavon, J. (20IOa). La diplomacia local de los gobiernos estatales en México (2000-20I0). México: Cide, DTEI 201.

Schiavon, J. y Velázquez Flores, R. (2010b). La incidencia de la opinión pública en la política exterior de México: teoría y realidad. México: Cide, DTEI 197. 
Schiavon, J. (20IOc). Opinión pública, preferencias y política exterior: México ante el mundo. Paradigmas y paradojas de la política exterior de México: 2006-2006. México: El Colegio de México, Cide.

Schiavon, J. y Alberro, I. (2oIod). Shaping or Constraining Foreign Policy? The Role of Mexican Public Opinion in the Response to the Iraq War. México: Cide, DTEI 202.

Schiavon, J. (2013). ¿Qué quieren los mexicanos en temas internacionales?: opinión pública y política exterior en México (2006-2012). Foro Internacional, vol. LIII, 3-4 (2I3-2I4), 5I7-536.

Schiavon, J. (2015). Una década de acción internacional de los gobiernos locales mexicanos (2005-2015). Revista Mexicana de Politica Exterior, núm. IO4, IO3-I27.

Toro, M.C. (ed., 2020). Los acuerdos comerciales regionales y el TLCAN. México: El Colegio de México, Centro de Estudios Internacionales.

Valdés, M.E. (coord., 20I2). Los problemas nacionales durante el gobierno de Felipe Calderón. México: Miguel Ángel Porrúa, UAM-I.

Vega Cánovas, G. (I99I). México ante el libre comercio con América del Norte. México: El Colegio de México, Centro de Estudios Internacionales.

Vega Cánovas, G. (2010). El Tratado de Libre Comercio: visión retrospectiva y retos a futuro. México: El Colegio de México, Centro de Estudios Internacionales.

Vega Cánovas, G. (2014). México y Estados Unidos. La economía política del libre comercio. Antología. México: El Colegio de México.

Verea Campos, M., Fernández de Castro, R. y Weintraub, S. (1998). Nueva agenda bilateral en la relación México-Estados Unidos. México: Fondo de Cultura Económica.

Verea Campos, M. (20I0). Los mexicanos en la política migratoria canadiense. Norteamérica, vol. 5 (I), 93-I27.

Verea Campos, M. (20I4). Immigration Trends after 20 years of NAFTA. Norteamérica, vol. 9(2), I09-I43. 